\title{
Induction of mesenchymal stem cell-like transformation in rat primary glial cells using hypoxia, mild hypothermia and growth factors
}

\author{
HUIPING WEI ${ }^{1}$, WENYUN ZHOU ${ }^{2}$, GUOZHU HU $^{3}$ and CHUNHUA SHI ${ }^{4}$ \\ Departments of ${ }^{1} \mathrm{Health}$ Care for Cadres and ${ }^{2}$ Prevention and Health Care, \\ ${ }^{3}$ Institute of Clinical Medicine and ${ }^{4}$ Department of Rheumatology and Immunology, \\ Jiangxi Provincial People's Hospital Affiliated to Nanchang University, Nanchang, Jiangxi 330006, P.R. China
}

Received June 9, 2020; Accepted November 6, 2020

DOI: $10.3892 / \mathrm{mmr} .2020 .11760$

\begin{abstract}
The transformation of rat primary glial cells into mesenchymal stem cells (MSCs) is intriguing as more seed cells can be harvested. The present study aimed to evaluate the effects of growth factors, hypoxia and mild hypothermia on the transformation of primary glial cells into MSCs. Rat primary glial cells were induced to differentiate by treatment with hypoxia, mild hypothermia and basic fibroblast growth factor (bFGF) and epidermal growth factor (EGF). Immunohistochemistry and western blotting were then used to determine the expression levels of glial fibrillary acidic protein (GFAP), nestin, musashi-1, neuron specific enolase (NSE) and neuronal nuclei (NeuN), in each treatment group. bFGF and EGF increased the proportion of $\mathrm{CD} 44^{+}$and $\mathrm{CD}_{105}{ }^{+}$cells, while anaerobic mild hypothermia increased the proportion of $\mathrm{CD} \mathrm{O}^{+}$cells. The combination of bFGF and EGF, and anaerobic mild hypothermia increased the proportion of $\mathrm{CD}^{2} 9^{+}$cells and significantly decreased the proportions of $\mathrm{GFAP}^{+}$cells and NSE ${ }^{+}$cells. Treatment of primary glial cells with bFGF and EGF increased the expression levels of nestin, Musashi-1, NSE and NeuN. Anaerobic mild hypothermia increased the expression levels of Musashi- 1 and decreased the expression levels of NSE and NeuN in glial cells. The results of the present study demonstrated that bFGF, EGF and anaerobic mild hypothermia treatments may promote the transformation of glial cells into MSC-like cells, and that the combination of these two treatments may have the optimal effect.
\end{abstract}

Correspondence to: Dr Chunhua Shi, Department of Rheumatology and Immunology, Jiangxi Provincial People's Hospital Affiliated to Nanchang University, 92 Aiguo Road, Nanchang, Jiangxi 330006, P.R. China

E-mail: shichunhuaaa@163.com

Key words: glial cells, mesenchymal stem cells, growth factors, anaerobic, hypothermia

\section{Introduction}

Cerebral ischemia and the hypoxia that arises from this condition are the direct causes of stroke and other cerebral diseases (1). Over recent years, mild hypothermia therapy and stem cell therapy have been introduced as a treatment option for patients suffering from these conditions (2). For example, randomized, double-blind, Phase III clinical trials have been carried out by two European groups to investigate the potential effects of hypothermia therapy over 6 months, demonstrating that treatment involving mild hypothermia resulted in good neurological recovery $(3,4)$. Additionally, experiments of cerebral infarction in a rat model demonstrated that mild hypothermia treatment can decrease the area of infarction and achieve good levels of recovery in terms of nerve function (5). In addition, there have been several successful cases of stem cell therapy and mild hypothermia combined with stem cell therapy for stroke in infants (6-8).

A previous study has suggested that basic fibroblast growth factor (bFGF) and epidermal growth factor (EGF) can promote the transformation of bone marrow-derived mesenchymal stem cells (MSCs) or adipose MSCs into neural cells (9). Glial cells are primary cells that can be isolated and cultured from the cerebral cortex; these represent a heterogeneous mixture of cell types that have the ability to proliferate and differentiate (10). The development of new induction methods to improve the efficiency of glial cell transformation into neural stem cells, MSCs would allow us to produce greater numbers of specific cells for neural repair treatments.

Previous studies injected the brains of rats with MSCs and achieved good levels of repair in the central nervous system $(11,12)$. In addition, a range of efficient methods have now been described to facilitate the acquisition of mesenchymal stem cells; these cells are important as they have the ability to differentiate into neural cells $(13,14)$. However, a previous study investigated the transformation of rat primary glial cells into MSCs (15). The present study hypothesized that treatment with mild hypothermia or growth factors may promote the differentiation of glial cells into MSCs, thus supplementing nerve cells that died due to hypoxia. The aim of the present study was to use a rat model to investigate the 
effects of cytokine induction and anaerobic mild hypothermia on the differentiation of primary glial cells.

\section{Materials and methods}

Primary isolation of rat glial cells. All animal procedures were approved by the Ethics Committee of Jiangxi Provincial People's Hospital Affiliated to Nanchang University (approval no. 2017BBG70066; Nanchang, China). All experiments involving animals were carried out in accordance with the Guide for the Care and Use of Laboratory Animals published by the National Institutes of Health (16). A total of ten specific pathogen-free neonatal Sprague-Dawley rats (1-3 days postnatal; 6-8 g; male:female, 1:1) were provided by the Animal Center of Jiangxi Provincial People's Hospital Affiliated to Nanchang University. The animals were housed in a specific pathogen-free environment at a temperature of $23 \pm 2^{\circ} \mathrm{C}$, with 45-65\% humidity, 12-h light/dark cycles, and free access to food and water. The animals were sacrificed by cervical dislocation and immersed in 75\% alcohol for 2-3 min on an ultra-clean table. D-Hank's solution (Gibco; Thermo Fisher Scientific, Inc.), containing a mixture of penicillin $(10,000 \mathrm{U} / \mathrm{ml})$ and streptomycin $(10 \mathrm{mg} / \mathrm{ml})$, was added to four petri dishes (labeled 1-4). First, the sterilized rats were transferred to dish number 1 . Their heads were removed and placed in dish number 2. The skulls were then separated at the brainstem, and the brain was quickly transferred to dish number 3 . The cortex was then freed and the meninges on the cortex were fully removed with tweezers and transferred to dish number 4 . The cortical tissue was then rinsed carefully in D-Hank's solution and then transferred to a vial containing penicillin $(10,000 \mathrm{U} / \mathrm{ml})$ and D-Hank's solution. The tissue suspension was then cut into tissue fragments that were $\sim 1 \mathrm{~mm}^{3}$ in size and then transferred to a centrifuge tube. An equivalent volume of $0.25 \%$ trypsin was added to the centrifuge tube, the contents were mixed carefully and then allowed to digest at $37^{\circ} \mathrm{C}$ for $15 \mathrm{~min}$. The digestion was terminated by adding three equivalent volumes of complete culture medium including DF12 (cat. no. 1859228; Gibco; Thermo Fisher Scientific, Inc.) and $20 \%$ fetal bovine serum (FBS; cat. no. 04-007-1 A; Biological Industries). The cell suspension was then mixed by gentle blowing with a suction tube and filtered with a 200-mesh, and the isolated cells were centrifuged at $850 \mathrm{xg}$ for $3 \mathrm{~min}$ at room temperature. The supernatant was discarded and the cell precipitation was suspended in DF12 medium with 20\% FBS. Finally, the cells were cultured with $5 \% \mathrm{CO}_{2}$ at $37^{\circ} \mathrm{C}$ until the first passage prior to subsequent experimentation.

Hypoxia, mild hypothermia and growthfactor treatments. Cells at $70 \%$ confluency were divided into eight groups for culture in normal culture medium (DF12 with 20\% FBS) as follows: Control-normal (astrocytes cultured at $37^{\circ} \mathrm{C}$ with $5 \% \mathrm{CO}_{2}$ ); control-hypothermia $\left(33^{\circ} \mathrm{C}, 5 \% \mathrm{CO}_{2}, 12 \mathrm{~h}\right)$; control-hypoxia $\left(37^{\circ} \mathrm{C}, 95 \% \mathrm{~N}_{2}, 5 \% \mathrm{CO}_{2}, 12 \mathrm{~h}\right)$; control-hypothermia + hypoxia; bFGF + EGF-normal; bFGF + EGF-hypothermia $\left(33^{\circ} \mathrm{C}\right.$, $\left.5 \% \mathrm{CO}_{2}, 12 \mathrm{~h}\right) ; \mathrm{bFGF}+$ EGF-hypoxia $\left(37^{\circ} \mathrm{C}, 95 \% \mathrm{~N}_{2}\right.$, $5 \% \mathrm{CO}_{2}, 12 \mathrm{~h}$ ); and bFGF + EGF-hypothermia + hypoxia. Cells in the bFGF + EGF groups received $10 \mathrm{ng} / \mathrm{ml}$ bFGF (cat. no. P1020-500; Novoprotein) and $20 \mathrm{ng} / \mathrm{ml}$ EGF (cat. no. REGFP-05011; Cyagen Biosciences, Inc.) for 7 days.
Hypothermia involved a reduction in the culture temperature from $37^{\circ} \mathrm{C}$ to $33^{\circ} \mathrm{C}$ for $12 \mathrm{~h}$. To mimic a hypoxic environment, cells were cultured in $95 \% \mathrm{~N}_{2}+5 \% \mathrm{CO}_{2}$ for $12 \mathrm{~h}$. The cells were treated for a total of 7 days and collected for subsequent experiments.

Immunocytochemical staining. Cells were fixed in $4 \%$ paraformaldehyde at room temperature for $1 \mathrm{~h}$. Following antigen retrieval by heating in a microwave in Tris/EDTA (pH 9.0), $3 \%$ hydrogen peroxide was used to block endogenous peroxidase activity for $15 \mathrm{~min}$ at room temperature. After non-specific blocking in 5\% BSA (HyClone; GE Healthcare Life Science) at room temperature for $2 \mathrm{~h}$, the cells were incubated overnight at $4{ }^{\circ} \mathrm{C}$ with primary antibodies against nestin (cat. no. OM264981; OmniAb; 1:250), glial fibrillary acidic protein (GFAP; cat. no. ab33922; Abcam; 1:500), neuronal nuclei (NeuN; cat. no. ab177487; Abcam; 1:500), Musashi-1 (cat. no. bs-20241r; BIOSS; 1:250) and neuron specific enolase (NSE; cat. no. bs-10445r; BIOSS; 1:500). The following morning, the cells were washed with PBS and then incubated with an HRP-conjugated goat anti-rabbit IgG H\&L secondary antibody (cat. no. ab6721; Abcam; $1: 500$ ) at $37^{\circ} \mathrm{C}$ for $30 \mathrm{~min}$. Subsequently, the cells were washed with PBS, and stained with 3,3'-diaminobenzidine for 5-10 $\mathrm{min}$ at room temperature. Cells were then re-washed in PBS for $1 \mathrm{~min}$ and stained with hematoxylin for $3 \mathrm{~min}$ at room temperature; this staining was then converted to a blue color using ethanol hydrochloride. Finally, cells were observed by light microscopy. ImagePro Plus (version 6.0; Media Cybernetics, Inc.) was used to measure the mean optical density of positive cells within three randomly selected fields of view at high magnification (x200).

Flow cytometry. Instrument parameters were adjusted by fluorescence homology control. Cells were washed twice with PBS and digested with $0.25 \%$ trypsin containing $0.02 \%$ EDTA. The cell suspension was then transferred into a $10-\mathrm{ml}$ centrifuge tube. Cells were collected from each treatment group by centrifugation at $850 \mathrm{x}$ g for $3 \mathrm{~min}$ at room temperature. Next, $1 \mathrm{ml}$ of PBS solution was added to each tube and centrifuged at $1,700 \mathrm{xg}$ for $1 \mathrm{~min}$ at room temperature. The supernatant was discarded, and $5 \times 10^{5}$ cells were collected in $300 \mathrm{ml}$ PBS. Subsequently, $300 \mu \mathrm{l} 2 \mathrm{X}$ binding buffer and $5 \mu \mathrm{l}$ of the following antibodies were added to each tube: Mouse anti-CD90-FITC (cat. no. 561973; BD Biosciences; 1:100), mouse anti-CD29-PE (cat. no. 102207; BioLegend, Inc.; 1:100), mouse anti-CD44-PE-cy7 (cat. no. ab4679; Abcam; 1:100) and mouse anti-CD105-APC (cat. no. 17-1051-80; eBioscience; Thermo Fisher Scientific, Inc.; 1:100). The tubes were mixed carefully and incubated at room temperature in the dark for $10 \mathrm{~min}$. Multichannel fluorescence counting was then performed on a FACSCalibur flow cytometer (BD Biosciences). The combinations of CD105/CD90 and CD29/CD44 were used in the flow cytometry experiments. Data were analyzed using FlowJo software (version 7.6; FlowJo, LLC).

Western blotting. Cells from each treatment group were mixed with RIPA solution (Beyotime Institute of Biotechnology) and incubated at $4^{\circ} \mathrm{C}$ for $30 \mathrm{~min}$ to create a lysed suspension containing protein extract. The extracts were then centrifuged 
at $8,500 \mathrm{xg}$ for $10 \mathrm{~min}$ at $4^{\circ} \mathrm{C}$; the supernatant, containing the total protein extract, was retained for analysis. Next, a bicinchoninic acid kit (Beyotime Institute of Biotechnology) was used to determine the concentration of each protein extract. Proteins $(20 \mu \mathrm{g})$ were then separated by $10 \%$ SDS-PAGE, and then transferred to PVDF membranes. After blocking in 5\% skimmed milk at room temperature for $2 \mathrm{~h}$, membranes were then incubated overnight at $4^{\circ} \mathrm{C}$ with a range of primary antibodies, including: Nestin (cat. no. OM264981; OMNIAB; 1:250), GFAP (cat. no. ab33922; Abcam; 1:500), NeuN (cat. no. ab177487; Abcam; 1:500), Musashi-1 (cat. no. bs-20241r: BIOSS; 1:250), NSE (cat. no. bs-10445r; BIOSS; 1:500) and GAPDH (cat. no. ab8245; Abcam; 1:1,000). The following morning, the membranes were washed with PBS and incubated with an HRP goat anti-rabbit IgG H\&L secondary antibody (cat. no. ab6721; Abcam; 1:500) or HRP goat anti-mouse IgG H\&L secondary antibody (cat. no. ab6789; Abcam; 1:500) at room temperature for 1-2 h. The membranes were then developed using ECL exposure solution (cat. no. SW2010-1; Beijing Solarbio Science \& Technology Co., Ltd.). Quantity one software (version 4.6; Bio-Rad Laboratories, Inc.) was used to analyze the gray value of specific bands of interest.

Statistical analysis. Data are presented as the mean \pm SD of six repeats. Comparisons among multiple groups were analyzed using two-way ANOVA followed by a Bonferroni post-hoc test. All data were analyzed using SPSS (version 19.0; IBM Corp.). $\mathrm{P}<0.05$ was considered to indicate a statistically significant difference

\section{Results}

Glial cell identification. Data relating to the immunohistochemical detection of GFAP are shown in Fig. 1. Primary cultured glial cells expressed GFAP, indicating that these cells exhibited low levels of differentiation. Some of these cells expressed strong immunofluorescence for GFAP; these cells were polygonal in shape and were bifurcated, thus indicating that they were astrocytes. However, $\sim 40 \%$ cells in the staining were GFAP- cells, which were small in size. These cells may not be in healthy conditions.

Identification of differentiation clusters by flow cytometry. Flow cytometry was used to detect clusters of differentiated cells (CD44, CD29, CD90 and CD105) associated with MSCs. Under normal conditions, bFGF and EGF treatment increased the proportion of $\mathrm{CD} 105^{+}$cells from $<1$ to $\sim 30 \%$ $(\mathrm{P}<0.05$; Figs. 2 and 3A), and also significantly increased the proportion of $\mathrm{CD} 44^{+}$and $\mathrm{CD}^{+}$cells compared with the control group $(\mathrm{P}<0.05$; Figs. 2 , $3 \mathrm{~B}$ and $\mathrm{C})$. However, the proportion of $\mathrm{CD} 29^{+}$cells significantly decreased from $\sim 60$ to $\sim 40 \%$ following bFGF and EGF treatment compared with the control group under normal conditions $(\mathrm{P}<0.05$; Figs. 2 and 3D). The combined treatment of anaerobic mild hypothermia, bFGF and EGF led to an increase in the proportion of $\mathrm{CD} 29^{+}$cells to $\sim 60 \%$ compared with the control group ( $\mathrm{P}<0.05$; Figs. 2 and 3D). Additionally, anaerobic mild hypothermia treatment increased the proportion of $\mathrm{CD}_{4} 4^{+}, \mathrm{CD} 90^{+}$and $\mathrm{CD} 105^{+}$cells compared with the normal group ( $\mathrm{P}<0.05$; Figs. 2 and $3 \mathrm{~A}-\mathrm{C})$, although anaerobic mild

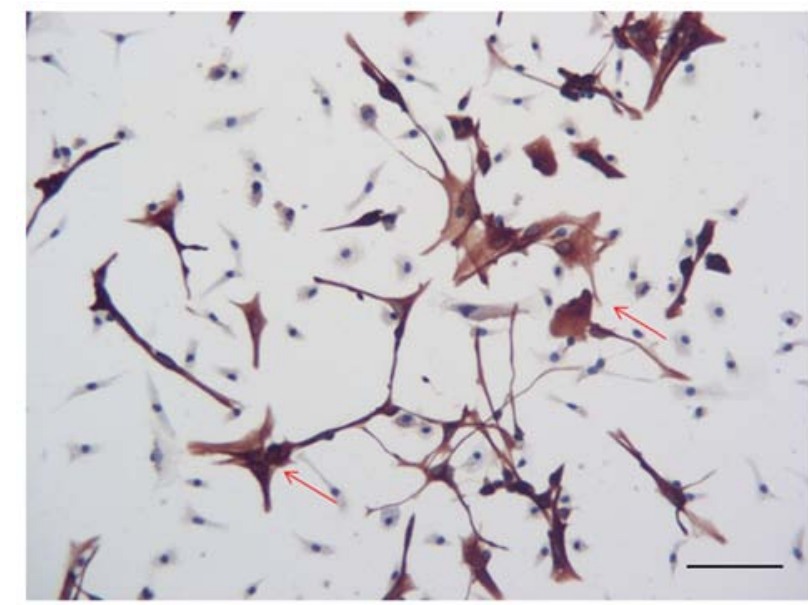

Figure 1. Primary cultured glial cells express glial fibrillary acidic protein Immunocytochemical methods were used to successfully identify astrocytes (marked by red arrows). Blue color indicates nuclei stained by hematoxylin. Scale bar, $20 \mu \mathrm{m}$.

hypothermia treatment with bFGF and EGF did not show a synergistic effect with regards to increasing the proportion of $\mathrm{CD} 44^{+}$and $\mathrm{CD} 90^{+}$clusters compared with the normal group (P>0.05; Figs. 2 and $3 \mathrm{~A}-\mathrm{C})$.

Growth factor and anaerobic mild hypothermia treatment decreases the expression levels of NSE, NeuN and GFAP, but promotes the expression levels of nestin and Musashi-1. Cells from the control-normal group and the bFGF + EGF-hypoxia + hypothermia group were tested by immunocytochemistry to determine the expression levels of a range of marker genes that are specific for neural cells, including GFAP, nestin, musashi-1, NSE and NeuN (Fig. 4). Compared with normal cultured glial cells, cells that were treated with anaerobic mild hypothermia, bFGF and EGF demonstrated a decrease in the proportions of $\mathrm{GFAP}^{+}, \mathrm{NSE}^{+}$and $\mathrm{NeuN}^{+}$cells, but an increase in the proportions of Musashi-1 $1^{+}$and Nestin ${ }^{+}$ cells; additionally, these cells tended to grow flat on the wall of culture dishes with fewer clusters (Fig. 4).

Western blotting was performed to detect specific cellular markers. Growth factor treatment (bFGF and EGF) led to an increase in the expression levels of nestin and Musashi-1, and a decrease in the expression levels of NSE and NeuN under normal conditions compared with control cells (Figs. 5 and 6). Anaerobic mild hypothermia treatment increased the expression levels of Musashi-1, but decreased the expression levels of NSE and NeuN in glial cells compared with the normal group. Additionally, anaerobic mild hypothermia treatment significantly decreased GFAP expression compared with the control-normal group ( $\mathrm{P}<0.05$; Figs. 5 and 6). Additionally, the combination of growth factors and anaerobic mild hypothermia treatments had synergistic effects on the inhibition of GFAP when compared with the bFGF + EGF + normal group $(\mathrm{P}<0.05$; Figs. 5 and 6$)$.

\section{Discussion}

According to the classical biological view, cell differentiation is unidirectional; in normal tissues, stem cells can differentiate 
A

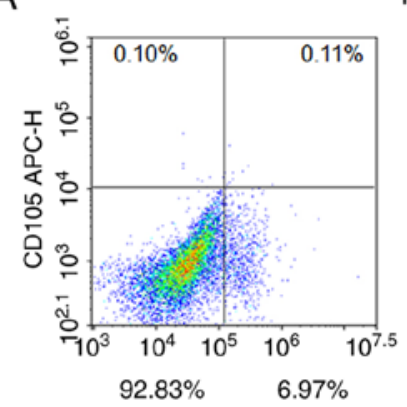

Normal

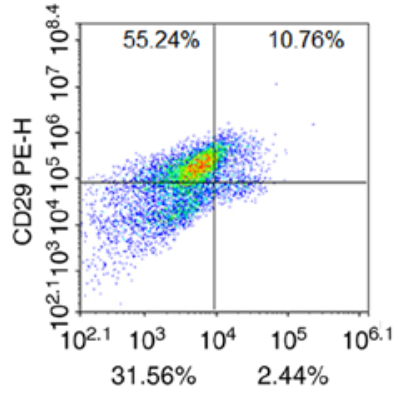

Hypoxia

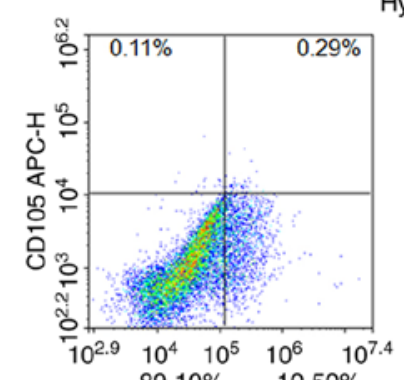

B
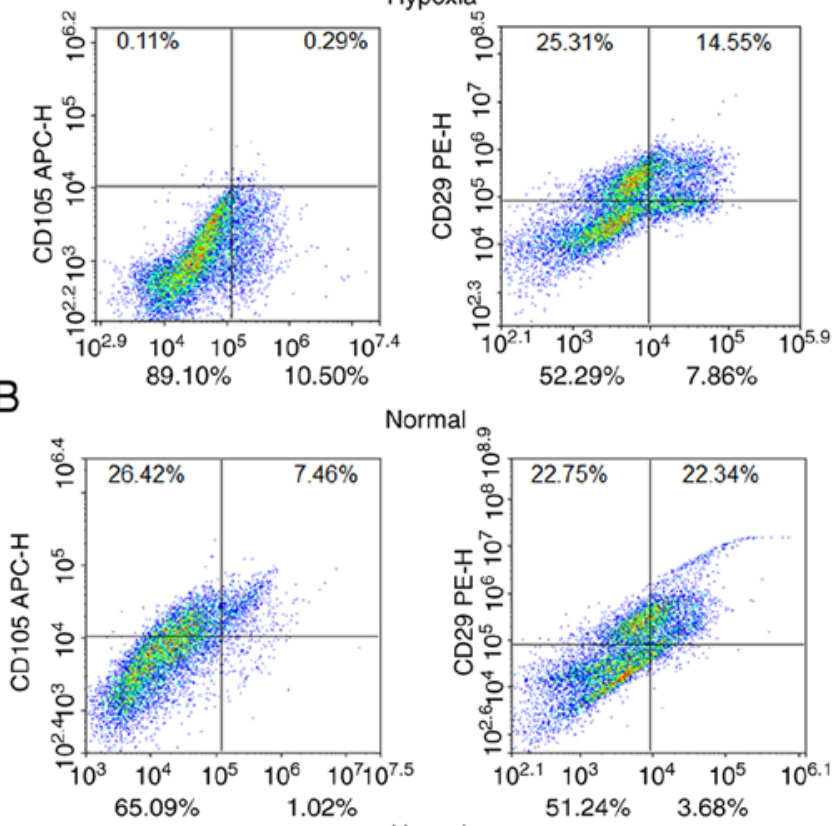

Normal
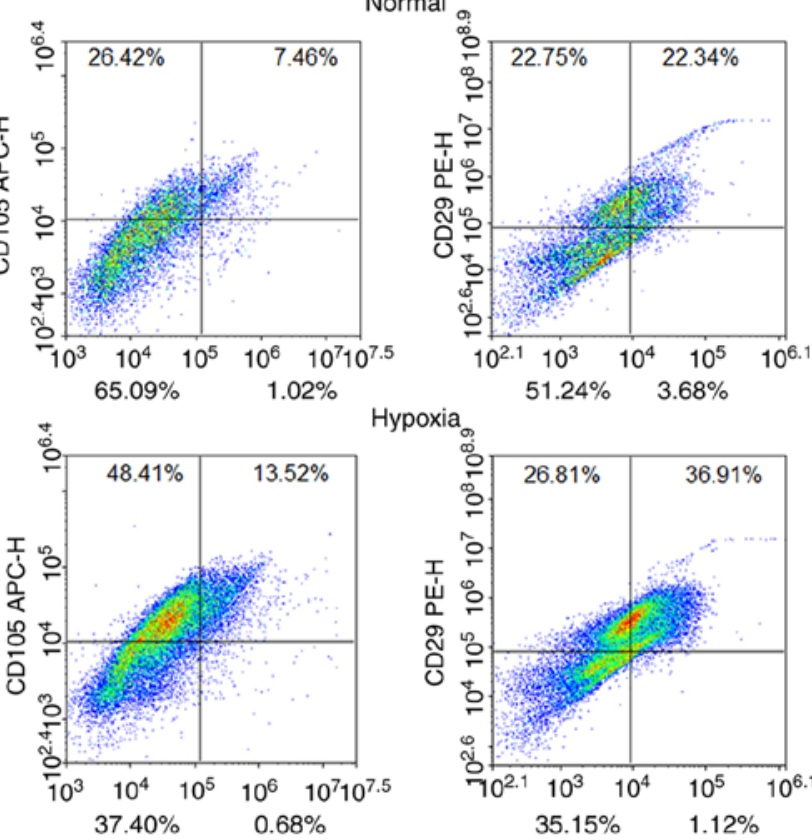

CD90 FITC-H
Hypoxia

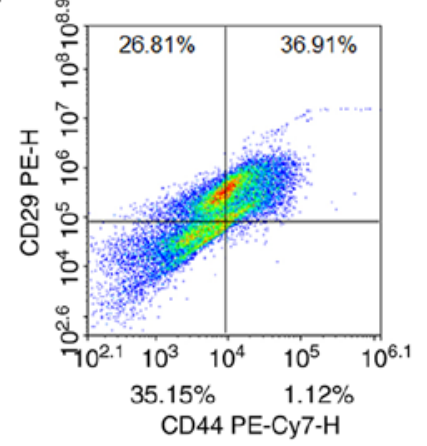

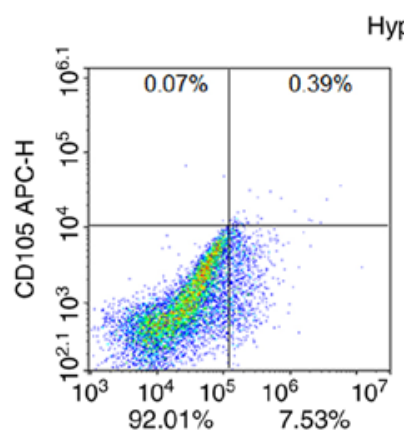

Hypothermia
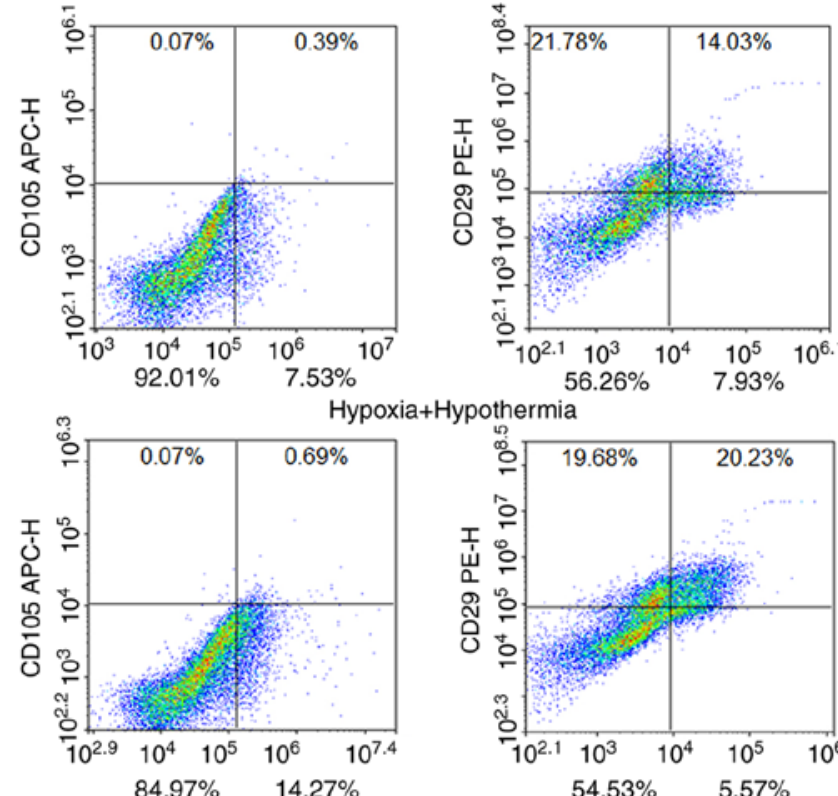

Hypoxia+Hypothermia

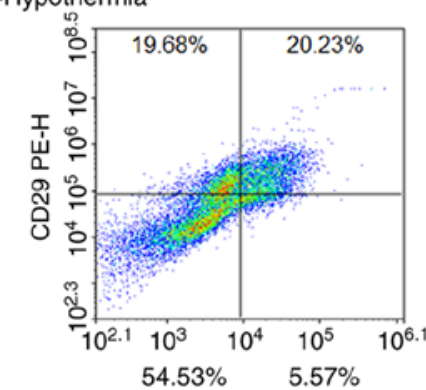

Hypothermia
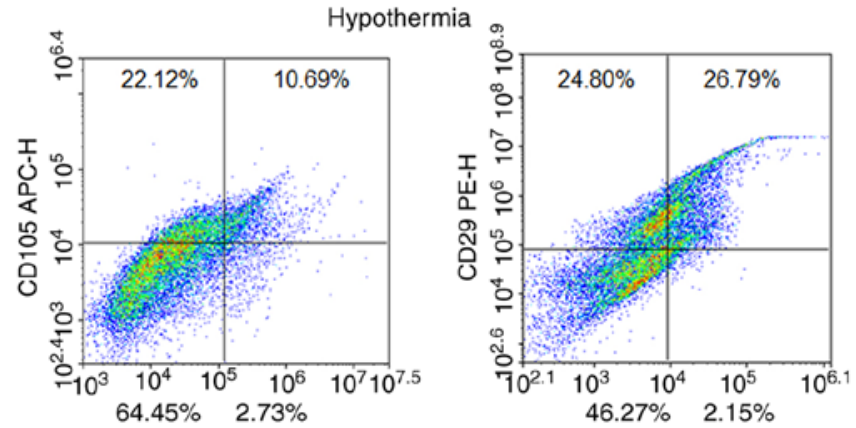

Hypoxia+Hypothermia

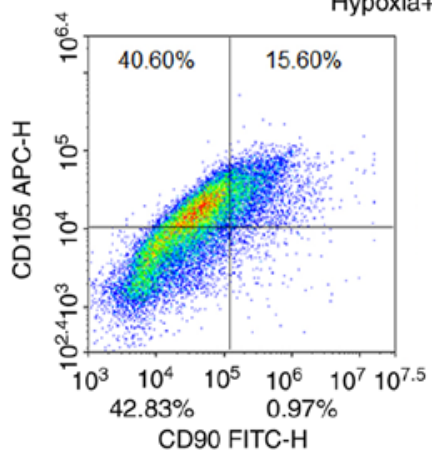

Figure 2. Identification of CD molecules by flow cytometry. Representative flow cytometry images of CD molecules (CD44, CD29, CD90 and CD105). (A) Control group. (B) bFGF + EGF group. bFGF, basic fibroblast growth factor; EGF, epidermal growth factor.

into a range of different cell types, such as neurons and glial cells (4). Although cells can be induced to differentiate into stem cells by a range of artificial techniques (17), it appears that under normal physiological conditions, differentiated cells cannot revert back to stem cells. However, this view has been challenged. A previous study found that glial cells in dental pulp can undergo a form of 'reverse differentiation' and revert back into stem cells (15). This discovery not only challenged the traditional concept, but also created a new option for the treatment of disease. The current study identified differences between growth factor treatment and mild hypothermia treatment with regards to the induction of glial cell differentiation, and that the combination of growth factor treatment and mild hypothermia treatment could improve the proportion of stem cell-like cells derived from a glial cell population.

Neuronal lineage markers and CD molecules were selected as indicators to evaluate the differentiation of glial cells under a range of different treatments involving growth factors, anaerobic conditions and mild hypothermic conditions. Nestin is known to be predominantly expressed in neural stem cells, but not in mature neurons; therefore, nestin is an effective marker for neural stem cells (18). Neuroblasts (neuroprogenitors) are monopotent stem cells with a certain potential for differentiation; these cells differentiate mainly into neurons, astrocytes and oligodendrocytes (19). GFAP, 

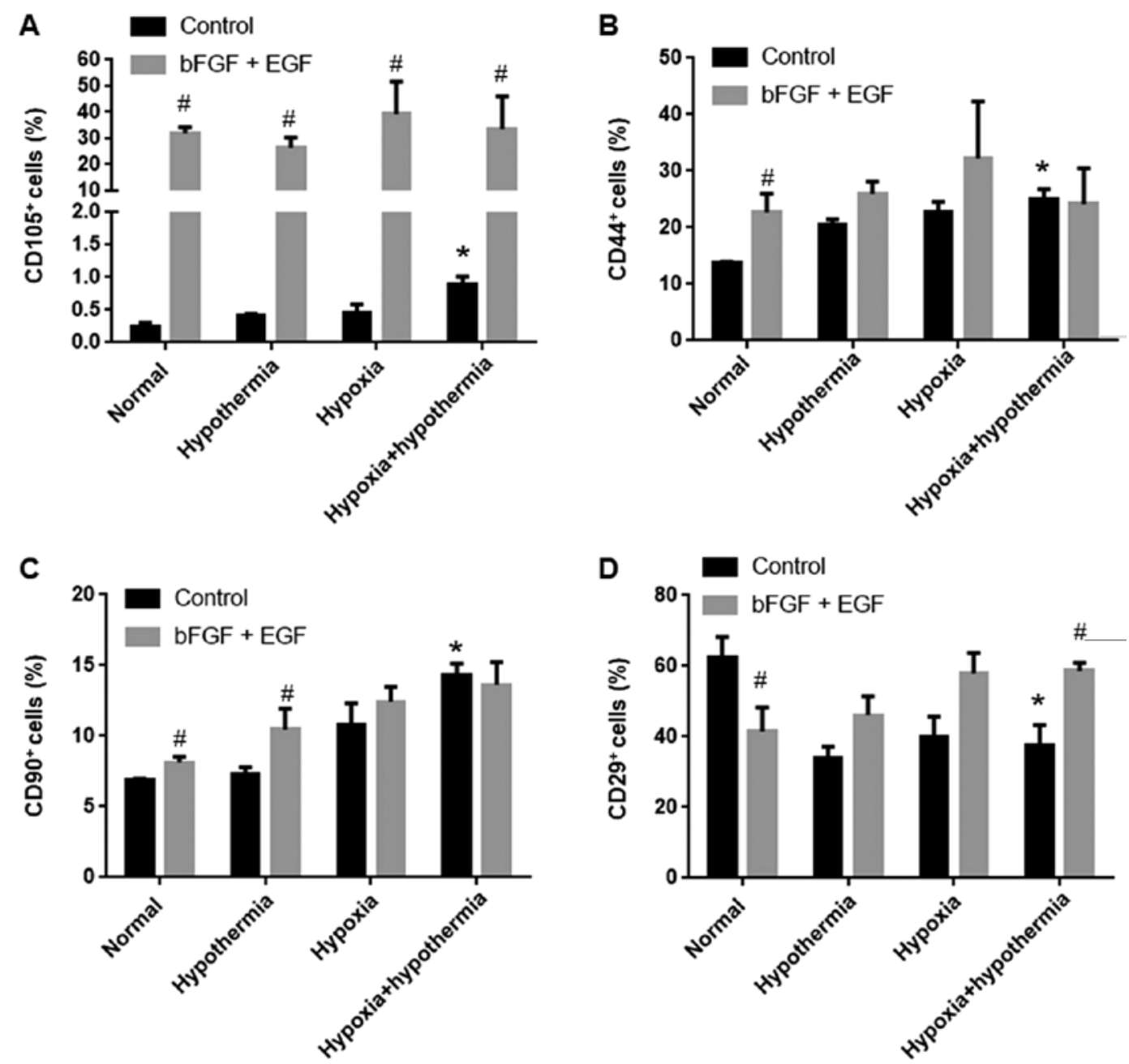

Figure 3. Quantification of the relative proportions of cells positive for CD44, CD29, CD90 and CD105. (A) CD105, (B) CD44, (C) CD90 and (D) CD29. ${ }^{*} \mathrm{P}<0.05$ vs. control-normal; ${ }^{\#} \mathrm{P}<0.05$ vs. corresponding control. bFGF, basic fibroblast growth factor; EGF, epidermal growth factor.

an established marker for neuroblasts, is also expressed in astrocytes (20) and is therefore commonly used to identify neuroblasts containing nestin. Musashi-1, an RNA-binding protein, is mainly expressed in mitotic neural stem cells and is therefore used to identify neural stem cells and neuroblasts (21). NeuN antigen is a nucleoprotein that serves a vital role in neurons (22); the positive expression of NeuN antigen indicates that neurons are no longer undergoing mitotic events (23). NSE is a cytoplasmic protein that is mainly expressed in mature neurons and also represents an effective marker for differentiated neurons (24). The detection of CD molecules is an effective method with which to identify MSCs (25). According to the International Society for Cellular Therapy, the simplest identification criterion for human MSCs is the presence of adherent human cells that exhibit positivity for CD90/Thy1 and CD105/Endoglin, as determined by flow cytometry $(26,27)$. However, this simple criterion cannot be readily applied to the CDs of non-human MSCs. For example, MSCs from mouse adipose tissue can be CD105', and MSCs from rat bone marrow can be CD90- (28). Therefore, the identification of mouse-derived MSCs should also consider positivity for CD29 and CD44 $(29,30)$.

The indicators selected for the present study provide information from two different perspectives. One perspective is to reflect the growth of MSCs in the nervous system by detecting the positivity of MSC transforming clusters on the surface of glial cells in response to different treatments. The other perspective is to measure the expression levels of genetic and protein markers in glial cells in response to different treatment conditions. The central nervous system also contains MSCs; when a large number of neural cells die, MSCs proliferate and then differentiate to help repair the nervous system injury (31). This is the theoretical basis of stem cell therapy, in which MSCs are injected into the brain. Growth factor induction is a common and effective way of promoting this proliferation and to increase the proportion of MSCs produced (29). In order to identify MSCs in an accurate manner, it is important to maintain a high ratio of positivity in specific CD clusters (32). In the present study, $\mathrm{CD} 105^{+}$cells accounted for $<0.5 \%$ of all glial cells in the normal state; this increased to $\sim 1 \%$ after hypoxia and mild hypothermia treatments, thus indicating that mild hypothermia treatments can slightly increase the proportion of MSCs after hypoxia. Additionally, the present study demonstrated that this treatment increased the proportions of cells that were positive for CD105 and CD90 (to 30 and 20\%, respectively), although the proportion of cells that were positive for CD44 and CD90 did not 
A
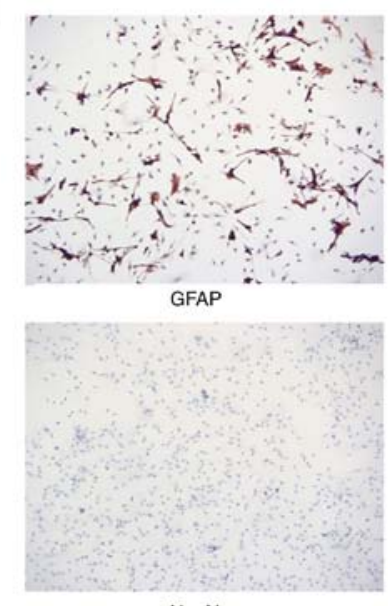

NeuN

B

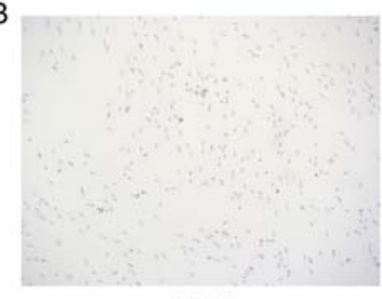

GFAP

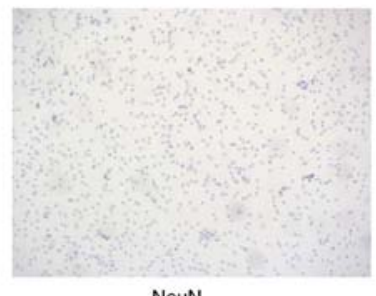

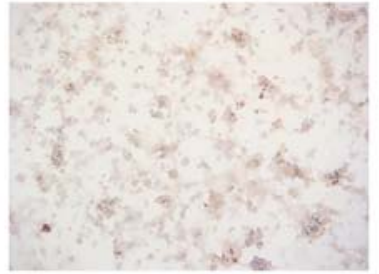

Musashi-1

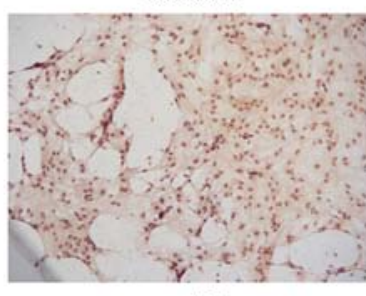

NSE

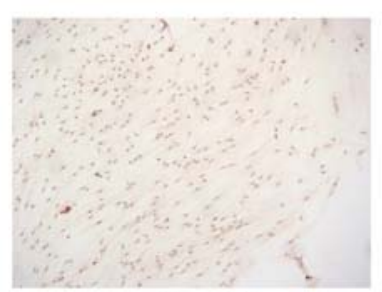

Musashi-1

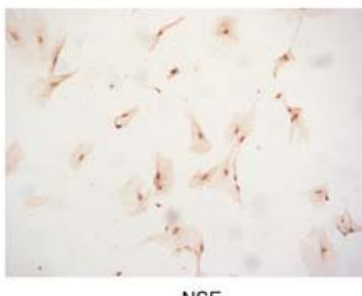

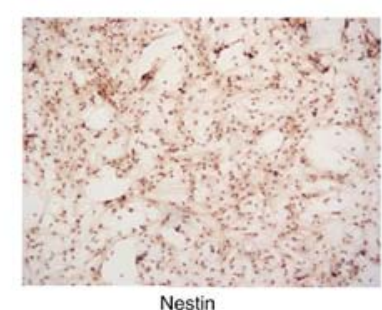

Nestin
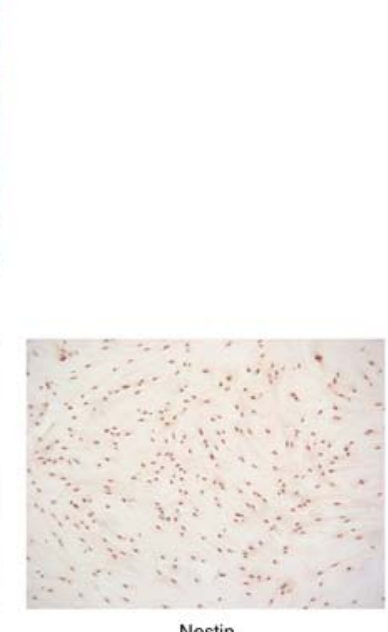

Nestin

Figure 4. Immunocytochemical detection of cellular markers. (A) Control-normal group, (B) bFGF + EGF-hypoxia + hypothermia group. The target protein is indicated by brown staining. Magnification, x100. bFGF, basic fibroblast growth factor; EGF, epidermal growth factor; GFAP, glial fibrillary acidic protein; NSE, neuron specific enolase; NeuN, neuronal nuclei.

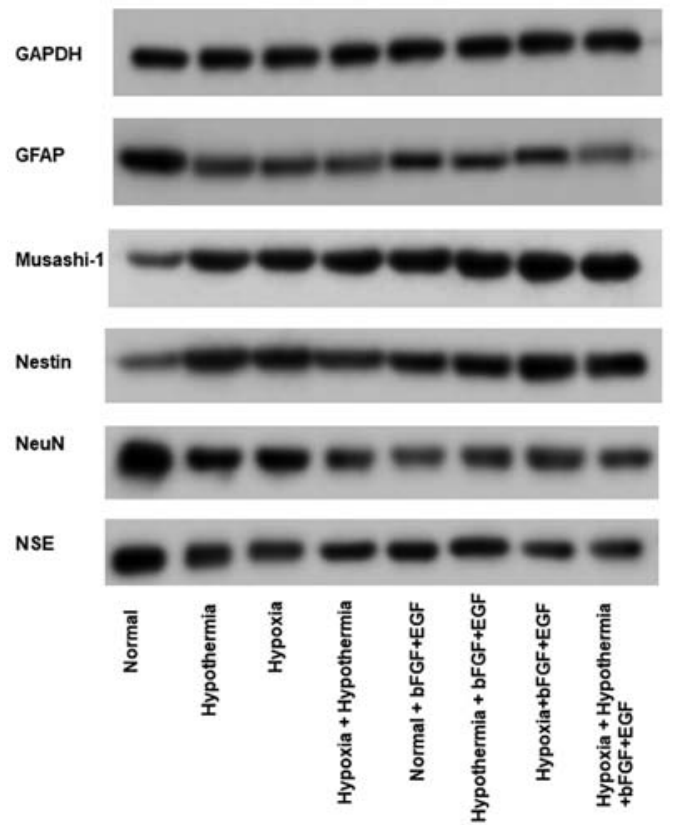

Figure 5. Detection of cellular markers by western blotting. Representative western blots for GFAP, nestin, musashi-1, NSE and NeuN, after treatment with bFGF + EGF and hypoxia + hypothermia. bFGF, basic fibroblast growth factor; EGF, epidermal growth factor; GFAP, glial fibrillary acidic protein; NSE, neuron specific enolase; NeuN, neuronal nuclei. change significantly. This indicated that growth factors may induce the proliferation of cells that are positive for both CD105 and CD29. However, these cells may not be MSCs; instead, these cells may be somatic cells exhibiting greater levels of differentiation. The proportion of MSCs that were positive for CD90 was $\sim 15 \%$. This is in accordance with the present immunocytochemistry results, which demonstrated that glial cells in the group receiving growth factors adopted a morphology that was more similar to fibroblasts.

During normal body function, different generations of cells must undergo processes that turn mature cells into stem cells (33). Although research relating to the induction of stem cells by acid has been questioned recently (34), there is no essential difference between the basic concept of this research and stem cell induction. The present study demonstrated that changes in the cellular environment may induce mature cells to become stem cells, although the identity of these specific environmental factors remains unknown. The results of the present study demonstrated that hypoxic mild hypothermia treatment or growth factor treatment upregulated the expression levels of nestin and Musashi-1 in differentiated neurons and downregulated the expression levels of NSE and NeuN in mature neurons. Hypoxia treatment, combined with mild hypothermia and growth factor treatment, further enhanced 

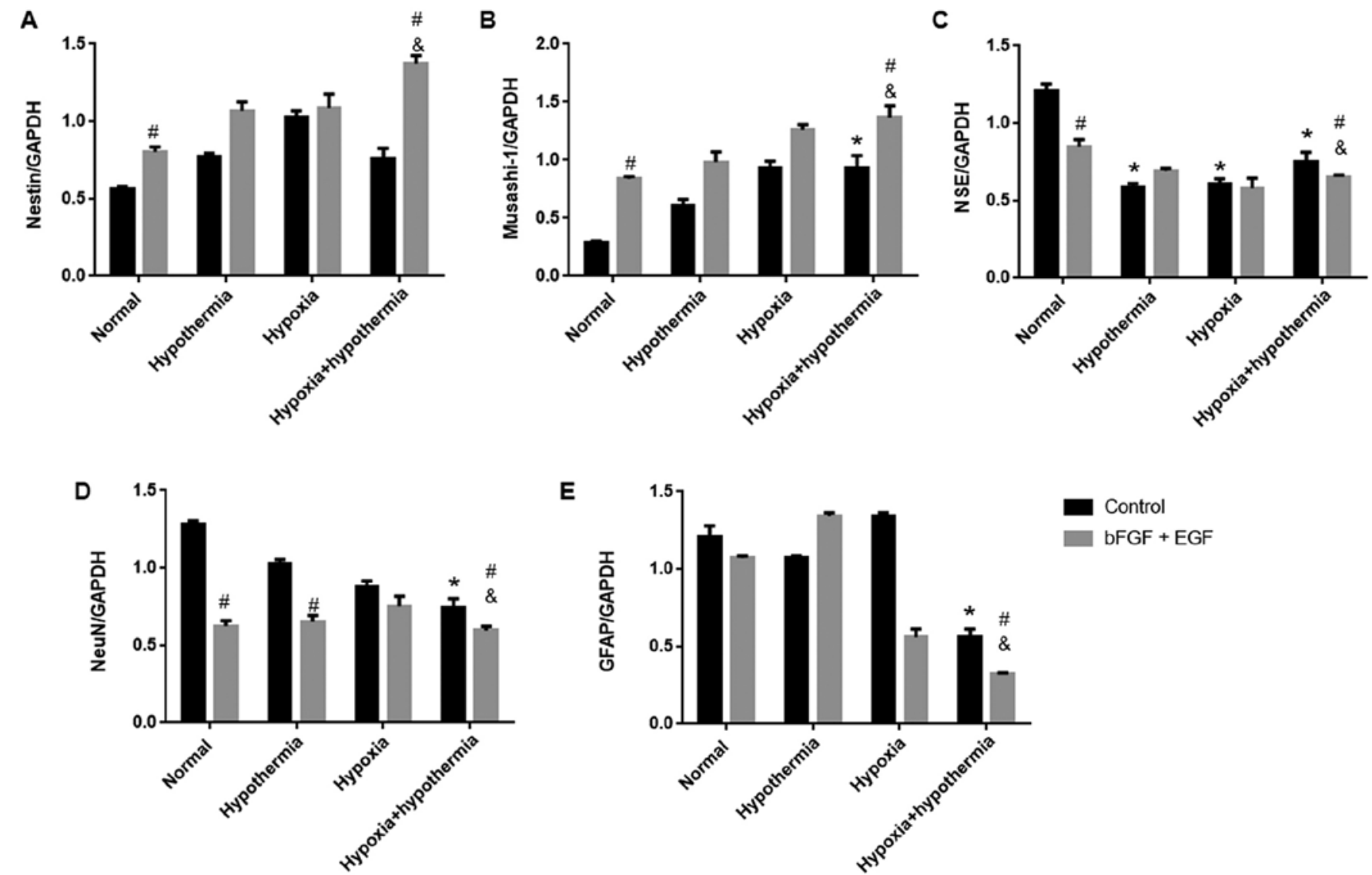

Figure 6. Quantitative data of the expression levels of different cellular markers. (A) nestin, (B) musashi-1, (C) NSE, (D) NeuN, (E) GFAP. ${ }^{*} \mathrm{P}<0.05$ vs. control-normal; ${ }^{\mathrm{P}} \mathrm{P}<0.05$ vs. corresponding control; ${ }^{\circledR} \mathrm{P}<0.05$ vs. control-bFGF + EGF. bFGF, basic fibroblast growth factor; EGF, epidermal growth factor; GFAP, glial fibrillary acidic protein; NSE, neuron specific enolase; NeuN, neuronal nuclei.

this effect. Additionally, the results of the present study demonstrated that the relative expression levels of GFAP were inhibited by mild hypothermia or growth factor treatment after hypoxia treatment. It is possible that neural stem cells are positive for GFAP, nestin and Musashi-1, whereas neuroblasts are positive for nestin and Musashi-1 (35). The observed decrease in GFAP expression may indicate that neural stem cells that are derived from MSCs have the ability to rapidly differentiate into nerve cells.

Previous studies have demonstrated that it is difficult to identify MSCs from various rat tissues using surface markers alone $(36,37)$. In the present study, nestin and Musashi-1 were selected as biomarkers for MSCs (38) and the induction of MSC-like transformation in rat primary glial cells by hypoxia, mild hypothermia and growth factors from the morphological aspect was verified. Moreover, CD29 and CD44 positivity supported the MSC-like characteristics, at least to some extent. However, these biomarkers and surface markers are not sufficient to prove the specific features of MSCs. Future work should aim to stimulate transformed cells into different types of neurons (39), which could provide further support for the hypothesis of the current study.

In conclusion, the results of the present study suggested that treatments involving bFGF and EGF, and anaerobic mild hypothermia may promote the transformation of glial cells into MSC-like cells, and that these effects were optimized when the two treatments were combined.

\section{Acknowledgements}

Not applicable.

\section{Funding}

No funding was received.

\section{Availability of data and materials}

The datasets used and/or analyzed during the current study are available from the corresponding author on reasonable request.

\section{Authors' contributions}

HW, WZ and GH performed the experiments and analyzed the data. HW and CS designed the study and wrote the manuscript. All authors read and approved the final manuscript.

\section{Ethics approval and consent to participate}

The present study was approved by the Ethics Committee of Jiangxi Provincial People's Hospital Affiliated to Nanchang University (Nanchang, China; approval no. 2017BBG70066). 


\section{Patient consent for publication}

Not applicable.

\section{Competing interests}

The authors declare that they have no competing interests.

\section{References}

1. Lee RHC, Lee MHH, Wu CYC, Silva ACE, Possoit HE, Hsieh TH, Minagar A and Lin HW: Cerebral ischemia and neuroregeneration. Neural Regen Res 13: 373-385, 2018.

2. Sun YJ, Zhang ZY, Fan B and Li GY: Neuroprotection by therapeutic hypothermia. Front Neurosci 13: 586, 2019.

3. Wassink G, Gunn ER, Drury PP, Bennet L and Gunn AJ: The mechanisms and treatment of asphyxial encephalopathy. Front Neurosci 8: 40, 2014.

4. Shankaran S: Outcomes of hypoxic-ischemic encephalopathy in neonates treated with hypothermia. Clin Perinatol 41: 149-159, 2014.

5. Darwazeh R and Yan Y: Mild hypothermia as a treatment for central nervous system injuries: Positive or negative effects. Neural Regen Res 8: 2677-2686, 2013.

6. Park WS, Sung SI, Ahn SY, Yoo HS, Sung DK, Im GH, Choi SJ and Chang YS: Hypothermia augments neuroprotective activity of mesenchymal stem cells for neonatal hypoxic-ischemic encephalopathy. PLoS One 10: e0120893, 2015.

7. Savitz SI, Cramer SC, Wechsler L and Consortium S: Stem cells as an emerging paradigm in stroke 3: Enhancing the development of clinical trials. Stroke 45: 634-639, 2014.

8. Cox CS Jr, Hetz RA, Liao GP, Aertker BM, Ewing-Cobbs L, Juranek J, Savitz SI, Jackson ML, Romanowska-Pawliczek AM, Triolo F, et al: Treatment of severe adult traumatic brain injury using bone marrow mononuclear cells. Stem Cells 35: 1065-1079, 2017.

9. Ullah I, Subbarao RB and Rho GJ: Human mesenchymal stem cells-current trends and future prospective. Biosci Rep 35 e00191, 2015 .

10. Kriegstein A and Alvarez-Buylla A: The glial nature of embryonic and adult neural stem cells. Annu Rev Neurosci 32: 149-184, 2009.

11. van Velthoven CT, Kavelaars A, van Bel F and Heijnen CJ Repeated mesenchymal stem cell treatment after neonatal hypoxia-ischemia has distinct effects on formation and maturation of new neurons and oligodendrocytes leading to restoration of damage, corticospinal motor tract activity, and sensorimotor function. J Neurosci 30: 9603-9611, 2010.

12. Parolini O, AlvianoF,BergwerfI,Boraschi D, De BariC,De Waele P, Dominici M, Evangelista M, Falk W, Hennerbichler S, et al: Toward cell therapy using placenta-derived cells: Disease mechanisms, cell biology, preclinical studies, and regulatory aspects at the round table. Stem Cells Dev 19: 143-154, 2010.

13. Liu L and Ho C: Mesenchymal stem cell preparation and transfection-free ferumoxytol labeling for MRI cell tracking. Curr Protoc Stem Cell Biol 43: 2B.7.1-2B.7.14, 2017.

14. Liu L, Tseng L, Ye Q, Wu YL, Bain DJ and Ho C: A new method for preparing mesenchymal stem cells and labeling with ferumoxytol for cell tracking by MRI. Sci Rep 6: 26271, 2016.

15. Luo L, He Y, Wang X, Key B, Lee BH, Li H and Ye Q: Potential roles of dental pulp stem cells in neural regeneration and repair Stem Cells Int 2018: 1731289, 2018.

16. National Research Council: Guide for the Care and Use of Laboratory Animals. 8th edition. National Academies Press, Washington, DC, 2011.

17. Donovan PJ and de Miguel MP: Turning germ cells into stem cells. Curr Opin Genet Dev 13: 463-471, 2003.

18. Homem CC, Repic M and Knoblich JA: Proliferation control in neural stem and progenitor cells. Nat Rev Neurosci 16: 647-659, 2015.

19. Jefferis GS and Livet J: Sparse and combinatorial neuron labelling. Curr Opin Neurobiol 22: 101-110, 2012.
20. Song Z, Shen F, Zhang Z, Wu S and Zhu G: Calpain inhibition ameliorates depression-like behaviors by reducing inflammation and promoting synaptic protein expression in the hippocampus. Neuropharmacology 174: 108175, 2020.

21. Mirsadeghi S, Shahbazi E, Hemmesi K, Nemati S, Baharvand H, Mirnajafi-Zadeh J and Kiani S: Development of membrane ion channels during neural differentiation from human embryonic stem cells. Biochem Biophys Res Commun 491: 166-172, 2017.

22. Zhu G, Wang Y, Li J and Wang J: Chronic treatment with ginsenoside Rg1 promotes memory and hippocampal long-term potentiation in middle-aged mice. Neuroscience 292: 81-89, 2015.

23. Gusel'nikova VV and Korzhevskiy DE: NeuN As a neuronal nuclear antigen and neuron differentiation marker. Acta Naturae 7: 42-47, 2015.

24. Sarnat HB: Clinical neuropathology practice guide 5-2013: Markers of neuronal maturation. Clin Neuropathol 32: 340-369, 2013.

25. Pittenger MF, Discher DE, Peault BM, Phinney DG, Hare JM and Caplan AI: Mesenchymal stem cell perspective: Cell biology to clinical progress. NPJ Regen Med 4: 22, 2019.

26. Lavezzi AM, Corna MF and Matturri L: Neuronal nuclear antigen (NeuN): A useful marker of neuronal immaturity in sudden unexplained perinatal death. J Neurol Sci 329: 45-50, 2013.

27. Galipeau J and Krampera M: The challenge of defining mesenchymal stromal cell potency assays and their potential use as release criteria. Cytotherapy 17: 125-127, 2015.

28. Lv FJ, Tuan RS, Cheung KM and Leung VY: Concise review: The surface markers and identity of human mesenchymal stem cells. Stem Cells 32: 1408-1419, 2014.

29. Zhu H, Guo ZK, Jiang XX, Li H, Wang XY, Yao HY, Zhang Y and Mao N: A protocol for isolation and culture of mesenchymal stem cells from mouse compact bone. Nat Protoc 5: 550-560, 2010.

30. Sági B, Maraghechi P, Urbán VS, Hegyi B, Szigeti A, Fajka-Boja R, Kudlik G, Német K, Monostori E, Gócza E and Uher F: Positional identity of murine mesenchymal stem cells resident in different organs is determined in the postsegmentation mesoderm. Stem Cells Dev 21: 814-828, 2012.

31. Nandoe Tewarie RS, Hurtado A, Bartels RH, Grotenhuis A and Oudega M: Stem cell-based therapies for spinal cord injury. J Spinal Cord Med 32: 105-114, 2009.

32. Maleki M, Ghanbarvand F, Reza Behvarz M, Ejtemaei M and Ghadirkhomi E: Comparison of mesenchymal stem cell markers in multiple human adult stem cells. Int J Stem Cells 7: 118-126, 2014.

33. Shyh-Chang $\mathrm{N}$ and $\mathrm{Ng} \mathrm{HH}$ : The metabolic programming of stem cells. Genes Dev 31: 336-346, 2017.

34. Kim EM, Manzar G and Zavazava N: Induced pluripotent stem cell-derived gamete-associated proteins incite rejection of induced pluripotent stem cells in syngeneic mice. Immunology 151: 191-197, 2017.

35. Campbell JG, Miller DC, Cundiff DD, Feng Q and Litofsky NS Neural stem/progenitor cells react to non-glial cns neoplasms. SpringerPlus 4: 53, 2015.

36. Sullivan MO, Gordon-Evans WJ, Fredericks LP, Kiefer K, Conzemius MG and Griffon DJ: Comparison of mesenchymal stem cell surface markers from bone marrow aspirates and adipose stromal vascular fraction sites. Front Vet Sci 2: 82, 2016

37. Lin CS, Xin ZC, Dai J and Lue TF: Commonly used mesenchymal stem cell markers and tracking labels: Limitations and challenges. Histol Histopathol 28: 1109-1116, 2013.

38. Xie L, Zeng X, Hu J and Chen Q: Characterization of nestin, a selective marker for bone marrow derived mesenchymal stem cells. Stem Cells Int 2015: 762098, 2015.

39. Khalil W, Tiraihi T, Soleimani M, Baheiraei N and Zibara K Conversion of neural stem cells into functional neuron-like cells by MicroRNA-218: Differential expression of functionality genes. Neurotox Res 38: 707-722, 2020. 